\title{
Bleaching of an intertidal coralline alga: untangling the effects of light, temperature, and desiccation
}

\author{
Patrick T. Martone ${ }^{1,2, *}$, Michael Alyono ${ }^{1}$, Shira Stites ${ }^{1}$ \\ ${ }^{1}$ Hopkins Marine Station of Stanford University, 120 Ocean View Blvd, Pacific Grove, California 93950, USA \\ ${ }^{2}$ Present address: Department of Botany, University of British Columbia, 6270 University Blvd, Vancouver, \\ British Columbia V6T 1Z4, Canada
}

\begin{abstract}
Intertidal macroalgae must tolerate temperature, light, and desiccation stresses when the tide recedes, and differences in physiological tolerance to these environmental stresses contribute directly to zonation patterns and community structure along the shore. When low tides occur on particularly hot sunny days, seaweeds may sustain physiological damage, lose pigment, and 'bleach.' Because bleaching events often occur when temperature, light, and desiccation stresses coincide, their precise cause is not understood. We conducted fully factorial laboratory manipulations to explore the individual and interactive effects of temperature, light, and desiccation on acute pigment loss in the intertidal coralline Calliarthron tuberculosum (Postels \& Ruprecht) E. Y. Dawson. Findings suggest that desiccation is the most significant contributor to bleaching; desiccating fronds even bleached in the dark at $15^{\circ} \mathrm{C}$. Susceptibility to desiccation may explain why mid-intertidal C. tuberculosum fronds are rarely found outside tidepools. Light and temperature had only marginal effects on pigment loss, although stresses interacted with increasing significance through time. When combined, temperature, light, and desiccation stresses were capable of inducing, on average, $50 \%$ pigment loss in C. tuberculosum within 24 min of emersion. These physiological data could be used in conjunction with environmental datasets to generate 'ecomechanical' models to predict future bleaching events and their ecological consequences under hypothetical climate change scenarios.
\end{abstract}

KEY WORDS: Calliarthron tuberculosum - Coralline algae $\cdot$ Desiccation $\cdot$ Ecomechanics $\cdot$ Light Physiology $\cdot$ Pigmentation $\cdot$ Temperature $\cdot$ Zonation

\section{INTRODUCTION}

Macroalgae that inhabit the intertidal zone of waveswept rocky shores must tolerate a wide range of physiological stresses on a daily basis. When the tide recedes, these marine organisms are exposed to terrestrial conditions in which they face increased temperature, light, and desiccation stresses. Past studies have shown that differences in tolerance to these environmental stresses contribute directly to zonation patterns, biogeographic distributions, and community structure along the shore (Mathieson \& Burns 1971, Johnson et al. 1974, Smith \& Berry 1986, Davison \& Pearson 1996). Thus, understanding physiological lim- its of individual species may help explain current species distributions and improve predictions of species responses to environmental shifts associated with climate change (e.g. Mykles et al. 2010, Portner 2010, Somero 2010).

Marine macroalgae possess a broad repertoire of defenses to protect them from environmental stresses during a typical low tide. For example, to combat temperature stress, algae may upregulate heat-shock proteins (HSPs) to maintain metabolic function as temperatures rise (e.g. Li \& Brawley 2004, Henkel \& Hofmann 2008). To slow dehydration, some algae retain water by growing as a dense turf (Hay 1981, Padilla 1984, Taylor \& Hay 1984) or as a water-filled sac (Oates 1985, 
Matta \& Chapman 1995). Other algae readily dehydrate, only to rehydrate and recover when the tide returns (Bell 1993, Lipkin et al. 1993). To avoid photoinhibition, macroalgae may adjust their pigment composition in high light environments (e.g. Beach \& Smith 1996) or dissipate light energy as heat (Fork et al. 1986).

However, when low tides occur on particularly hot, sunny days, intertidal macroalgae often sustain physiological damage and 'bleach' (e.g. Hodgson 1981, Kain \& Norton 1990, Scrosati \& DeWreede 1998, Hunt \& Denny 2008). Algal bleaching results in a degradation and loss of photosynthetic pigments, often leading to death (Hodgson 1981, Davison \& Pearson 1996; but see Biebl 1952, Clark et al. 2004, Irving et al. 2004). Although the consequences of bleaching events are clear, the precise cause is not well understood, in part because emersed algae experience some combination of light, temperature, and desiccation stresses. Bleaching may be caused primarily by one stressor or by an interaction of multiple stressors (e.g. Matta \& Chapman 1995). Assuming bleaching represents a breakdown of some physiological defense, we must pinpoint the environmental cause of bleaching events before we can explore physiological underpinnings and environmental thresholds.

Subtidal studies have demonstrated that, by clearing away surrounding kelp canopies, a sudden increase in light intensity is sufficient to induce bleaching in encrusting coralline algae (Irving et al. 2004). However, intertidal studies employing the same methodology are more difficult to interpret (Figueiredo et al. 2000) as clearing intertidal kelp canopies simultaneously affects light, desiccation, and temperature regimes. Experimental thinning of intertidal turfs (e.g. Hay 1981, Padilla 1984, Scrosati \& DeWreede 1998) are similarly confounded; observations of tips of algal turfs bleaching while moist, dark, cool cores remain healthy are open to interpretation (Hunt \& Denny 2008). Sudden shifts in the vertical distribution of intertidal algae after exposure to high air temperatures (Harley \& Paine 2009) may be just as easily caused by increased desiccation stress, since thallus temperature and desiccation are tightly linked (Bell 1995). Moreover, environmental stressors can interact in unanticipated ways. For example, dehydration has been shown to increase high-temperature tolerance in some intertidal seaweeds (e.g. Smith \& Berry 1986, Davison \& Pearson 1996, Hunt \& Denny 2008).

Here we examined the causes of bleaching in the articulated coralline alga Calliarthron tuberculosum (Postels \& Ruprecht) E. Y. Dawson (Corallinales, Rhodophyta), which grows in subtidal and intertidal habitats throughout the northeast Pacific. Intertidal fronds of C. tuberculosum generally live low on the shore $(<0.5 \mathrm{~m}$ tide height) or in mid-intertidal tidepools, where exposure to extreme temperature, desiccation, and light stresses is likely minimized during low tide. Fronds of C. tuberculosum growing near the surface of tidepools periodically bleach, revealing the bright white calcium carbonate deposited within coralline cell walls. Bleached segments of intertidal C. tuberculosum do not recover when maintained in re-circulating aquaria, and bleached fronds carefully tracked in the field disappear entirely within a few weeks (P. T. Martone unpubl. data). Thus, at least for C. tuberculosum, bleaching signifies that some physiological threshold has been irreversibly surpassed. Bleaching in intertidal algae may generally represent irreparable damage, since recovery from bleaching events is often due to growth of new fronds from basal crusts not re-pigmentation of bleached fronds (e.g. Scrosati \& DeWreede 1998, Harley \& Paine 2009). When basal crusts are damaged, then algae are likely killed entirely (Harley \& Paine 2009).

For Calliarthron. tuberculosum, bleaching events are indicative of habitat constraints imposed by environmental stressors, lending insight into why midintertidal fronds rarely emerge from tidepools. Coralline algae are central components of intertidal communities around the world, occupying primary space (e.g. Paine 1984, Steneck 1986) and providing both habitat (Dommasnes 1968, Akioka et al. 1999, Kelaher 2002) and settlement cues (e.g. Rumrill \& Cameron 1983, Williams et al. 2008) for many invertebrate taxa. Thus, understanding the precise environmental cause of bleaching will help explain the distribution of $C$. tuberculosum along the shore and inform the ecology of associated organisms.

In this study, we independently manipulated light, temperature, and desiccation stresses in a series of laboratory experiments to explore the causes of bleaching in Calliarthron tuberculosum. We first tested whether fronds bleach when submerged in tidepools, and then explored the individual and combined effects of light, temperature, and desiccation stresses on the rate and extent of bleaching in emersed fronds.

\section{MATERIALS AND METHODS}

Sample collection. Fronds of Calliarthron tuberculosum were taken from a single mid-intertidal tidepool (ca. $1.5 \times 0.5 \times 0.5 \mathrm{~m}$ deep) at Hopkins Marine Station (HMS) in Pacific Grove, California, USA $\left(36^{\circ} 37^{\prime} 18.2^{\prime} \mathrm{N}, \quad 121^{\circ} 54^{\prime} 14.7^{\prime} \mathrm{W}\right)$ during July 2008. Fronds were placed in a shaded outdoor water table for 1 to $2 \mathrm{~d}$ to stabilize after collection. The water table was covered with a tan-colored tarp that allowed little sun-

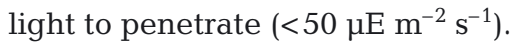


Environmental factors. Coralline fronds were bleached in the laboratory by exposing them to experimentally controlled levels of humidity, temperature, and light in fully factorial manipulations. Samples were placed on elevated platforms inside plastic containers, which were then sealed with clear plastic wrap (Fig. 1). For emersed treatments, relative humidity (RH) was controlled by adding desiccant or water to the bottom of the containers; $33 \%$ RH (representative of extremely dry sunny days at HMS; M. W. Denny pers. comm.) was maintained by adding an excess of magnesium chloride hexahydrate to tap water and $100 \%$ RH was maintained by adding only tap water. For submersed treatments, samples were submerged by filling containers with seawater. For all treatments, temperature was controlled by setting sample containers in a shallow temperature-controlled water bath. Light was controlled by placing the water bath and sample containers under 4 incandescent spotlights (120 W, 120 V, 1600 Lumens, R40) (Fig. 1). A transparent tray of water was positioned below the light bulbs to absorb infrared radiation, minimizing heat delivered to samples and facilitating temperature control using the water bath. Bulbs were physically lowered to yield $1000 \mathrm{~W} \mathrm{~m}^{-2}$ (representing full sun) or raised to yield

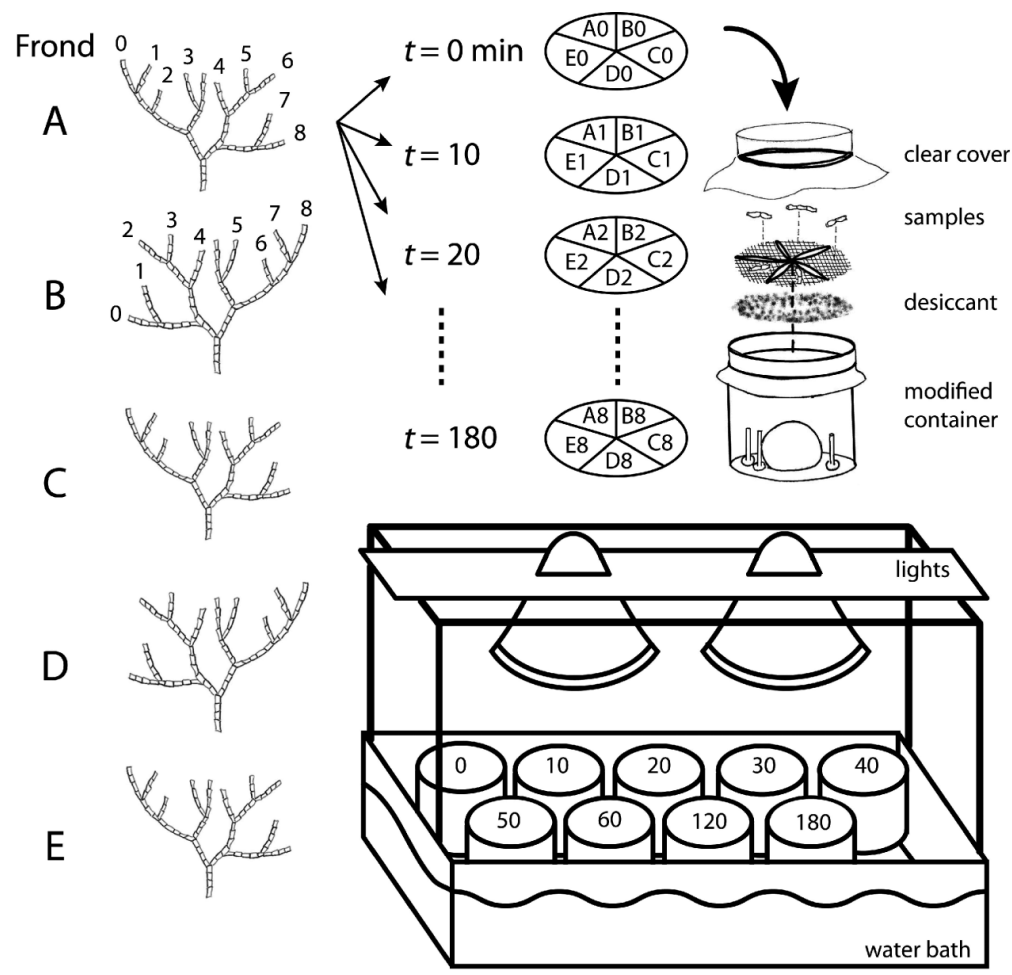

Fig. 1. Experimental set-up. Branches dissected from individual fronds were placed into separate sample containers, representing different time (min) intervals. Containers were sealed to control humidity, placed in a water bath to control temperature, and positioned under lights to control irradiance. See 'Materials and methods' for details
$370 \mathrm{~W} \mathrm{~m}^{-2}$ (representing overcast skies). The effects of UV radiation were not explored since preliminary experiments conducted outside under full sunlight yielded similar results (M. Alyono unpubl. data). For dark treatments $\left(0 \mathrm{~W} \mathrm{~m}^{-2}\right)$, sample containers were completely covered with aluminum foil.

Monitoring bleaching over time. To track the rate and extent of bleaching over time, $1 \mathrm{~cm}$ branches including apical meristems $(n=9)$ were dissected from each experimental frond $(n=5)$ and placed into 9 sample containers, corresponding to $0,10,20,30,40,50$, 60, 120, and 180 min time intervals (Fig. 1). Thus, each sample container contained 5 meristems representing 5 replicate fronds. Sample containers were sealed and then exposed to experimental bleaching treatments simultaneously. According to the 9 time intervals, 1 container was immediately removed from the experiment $(t=0 \mathrm{~min})$ as a control. Other containers were individually removed every $10 \mathrm{~min}$ for the first hour and then after 2 and $3 \mathrm{~h}$. Samples taken from containers removed from experimental treatment were immediately quenched in $15^{\circ} \mathrm{C}$ seawater, representing the return of the tide, and transferred back to the shaded water table described in 'Sample collection'. Samples were left in running seawater for $5 \mathrm{~d}$ to recover or bleach. This protocol permitted us to track the temporal progression of bleaching in individual fronds.

Thallus color and pigment analysis. After $5 \mathrm{~d}$, digital photos were taken of all samples under precisely the same light and camera settings. Sample color was measured from digital images using Image J software (v 1.36b, National Institutes of Health, Bethesda, Massachusetts, USA), which yielded an average shade value, from 0 (black) to 255 (white), for the surface of samples. Samples were stored at $-80^{\circ} \mathrm{C}$ for future pigment analysis.

To correlate color value to pigment loss, chlorophyll (chl) a content of a random selection of samples $(n=50)$ was quantified using spectrophotometric methods. The dry mass of samples of varying raw color value was recorded. Samples were then extracted at $4^{\circ} \mathrm{C}$ in the dark in $90 \%$ acetone overnight. Extract color was quantified using a spectrophotometer (Shimadzu UV-Visible Spectrophotometer UV-1601). Mass of chl a g $\mathrm{g}^{-1}$ of calcified biomass was calculated from spectrophotometric equations (Jeffrey \& Humphrey 1975). Chl a content was significantly correlated with average color value ( $\mathrm{chl} a=-0.0016 \times$ colorvalue $\left.+0.3107, R^{2}=0.68, p<0.001\right)$, and 
this equation was used to convert the color values of all samples to chl a content. Loss of pigment over time was quantified by dividing chl a content at each time step by the chl a content of samples at $t=0$, expressed as percent original chl a. For each frond, percentages were normalized by the highest percent chl a across all times to ensure that values were always $\leq 100 \%$.

Expt 1: Bleaching of submerged fronds. To explore whether submerged Calliarthron tuberculosum fronds bleach at high tide, sample containers were floodedwith seawater. Temperature $\left(2\right.$ levels: 15 and $30^{\circ} \mathrm{C}$ ) and light (3 levels: 0, 370, $1000 \mathrm{~W} \mathrm{~m}^{-2}$ ) were varied in fully factorial manipulations. Meristems from 5 fronds were subjected to each combination of environmental parameters (6 treatments) and monitored over $3 \mathrm{~h}$. Bleaching of samples ( $\mathrm{n}=270$ branches) was quantified as described above.

As little bleaching was documented in submerged fronds (even the most bleached branch retained approximately $74 \%$ pigmentation after $3 \mathrm{~h}$ ), only data from 10 and 180 min timepoints were compared. Percent data were arcsin-squareroot transformed and analyzed using a 3-way ANOVA with Temperature (2 levels: 15 and $30^{\circ} \mathrm{C}$ ), Light (3 levels: 0, 370, $1000 \mathrm{~W}$ $\mathrm{m}^{-2}$ ), and Time (2 levels: 10 and $180 \mathrm{~min}$ ) as orthogonal fixed factors. ANOVA results were further analyzed using Tukey's HSD post-hoc comparisons.

Expt 2: Bleaching of emersed fronds. To explore the induction of bleaching in Calliarthron. tuberculosum fronds emersed at low tide, Temperature (2 levels: 15 and $30^{\circ} \mathrm{C}$ ), Light (3 levels: 0, 370, $1000 \mathrm{~W} \mathrm{~m}^{-2}$ ), and Humidity ( 2 levels: 33 and 100\% RH) were varied in fully factorial manipulations. Meristems from 5 fronds were subjected to each combination of environmental parameters (12 treatments) and monitored over $3 \mathrm{~h}$. Bleaching of samples ( $\mathrm{n}=540$ branches) was quantified as described above.

Data were initially analyzed using repeatedmeasures ANOVA, including Time as a factor. Not surprisingly Time was significant, since pigmentation changed over the course of the experiments, as were most 2-, 3-, and 4-way interactions with other factors. Results from this preliminary analysis are not included here. Instead, to facilitate data interpretation and presentation, data were analyzed separately for 30, 60, and $120 \mathrm{~min}$ time intervals, representing low tides of 3 varying durations. Percent data were arcsinsquareroot transformed and analyzed using 3-way ANOVA with Temperature, Light, and Humidity as orthogonal fixed factors. ANOVA results were further analyzed using Tukey's HSD post-hoc comparisons. To explore the relative contribution of environmental effects to bleaching, variance components and magnitude of effects $\left(\omega^{2}\right)$ were calculated for each timepoint (see Graham \& Edwards 2001).
To explore the rate of pigment loss under various environmental stressors, bleaching data were analyzed to estimate the time required for fronds to lose $50 \%$ pigmentation. $15^{\circ} \mathrm{C}, 0 \mathrm{~W} \mathrm{~m}^{-2}$, and $100 \% \mathrm{RH}$ were considered non-stressful 'null' levels of temperature, light, and humidity, respectively, whereas $30^{\circ} \mathrm{C}$, $1000 \mathrm{~W} \mathrm{~m}^{-2}$, and $33 \% \mathrm{RH}$ were considered stressful. These stressors were respectively called 'Hot,' 'Bright,' and 'Dry'. Bleaching trials exploring all combinations of stressful and non-stressful treatments were analyzed. Treatment effects were described according to deviations from null conditions (e.g. 'Hot and Dry' treatment was $30^{\circ} \mathrm{C}, 33 \% \mathrm{RH}$, and $0 \mathrm{~W} \mathrm{~m}^{-2}$; 'Bright and Dry' was $15^{\circ} \mathrm{C}, 33 \% \mathrm{RH}$, and $1000 \mathrm{~W} \mathrm{~m}^{-2}$ ). Data documenting the decline of branch pigmentation over time were re-examined for each experimental frond $(n=5)$ in each treatment, and the mean time interval at which the pigment content of any branch dropped below $50 \%$ of initial pigmentation was noted. If pigment content of branches from any frond failed to drop below $50 \%$ during the $3 \mathrm{~h}$ experiment, the time to $50 \%$ bleached was estimated from a linear extrapolation of experimental data. Time data were log-transformed to ensure normal distributions and analyzed with a 3-way ANOVA with Temperature (2 levels), Light (2 levels), and Humidity (2 levels) as orthogonal fixed factors. ANOVA results were then analyzed using Tukey's HSD post-hoc comparisons.

Statistics. All statistical tests were performed using JMPIN (Version 4.0.4, SAS Institute, Cary, North Carolina, USA).

\section{RESULTS}

\section{Bleaching of submerged fronds}

Submerged fronds bleached very little over the course of the experiment. There was no significant effect of light on pigment loss, but there was a significant interaction between temperature and time (Table 1). After $3 \mathrm{~h}$, fronds submerged in $15^{\circ} \mathrm{C}$ seawater did not experience significant pigment loss (Fig. 2). Fronds

Table 1. ANOVA results for submerged bleaching experiment. Bold indicates significant effect. Temp: temperature

\begin{tabular}{|lccrc|}
\hline Effect & df & SS & F ratio & \multicolumn{1}{c|}{$\mathrm{p}$} \\
\hline Time & 1 & 0.35 & 16.86 & $\mathbf{< 0 . 0 0 1}$ \\
Light & 2 & 0.01 & 0.17 & 0.85 \\
Temp & 1 & 0.11 & 0.63 & $<\mathbf{0 . 0 5}$ \\
Time $\times$ Light & 2 & 0.03 & 5.24 & 0.54 \\
Time $\times$ Temp & 1 & 0.18 & 8.54 & $<\mathbf{0 . 0 1}$ \\
Light $\times$ Temp & 2 & 0.03 & 0.72 & 0.49 \\
Time $\times$ Light $\times$ Temp & 2 & 0.01 & 0.35 & 0.71 \\
\hline
\end{tabular}


submerged in $30^{\circ} \mathrm{C}$ seawater experienced significantly more bleaching than other treatments (Tukey's HSD, $\mathrm{p}<0.05)$, yet still retained $74.1 \pm 2.8 \%$ (mean \pm SEM) of original pigment content (Fig. 2).

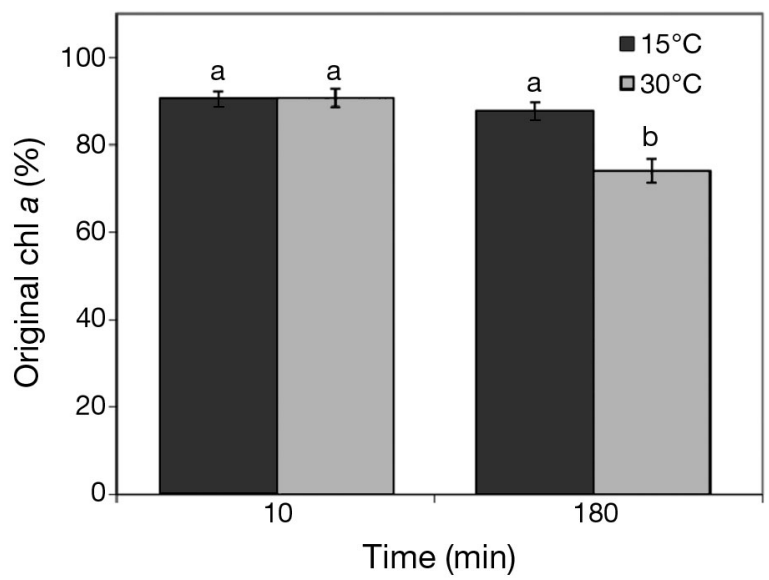

Fig. 2. Calliarthron tuberculosum. Effect of temperature and time on pigment loss (mean $\pm \mathrm{SE}$ ) of submerged fronds. Different letters indicate significant differences (Tukey's HSD, $\mathrm{p}<0.05)$

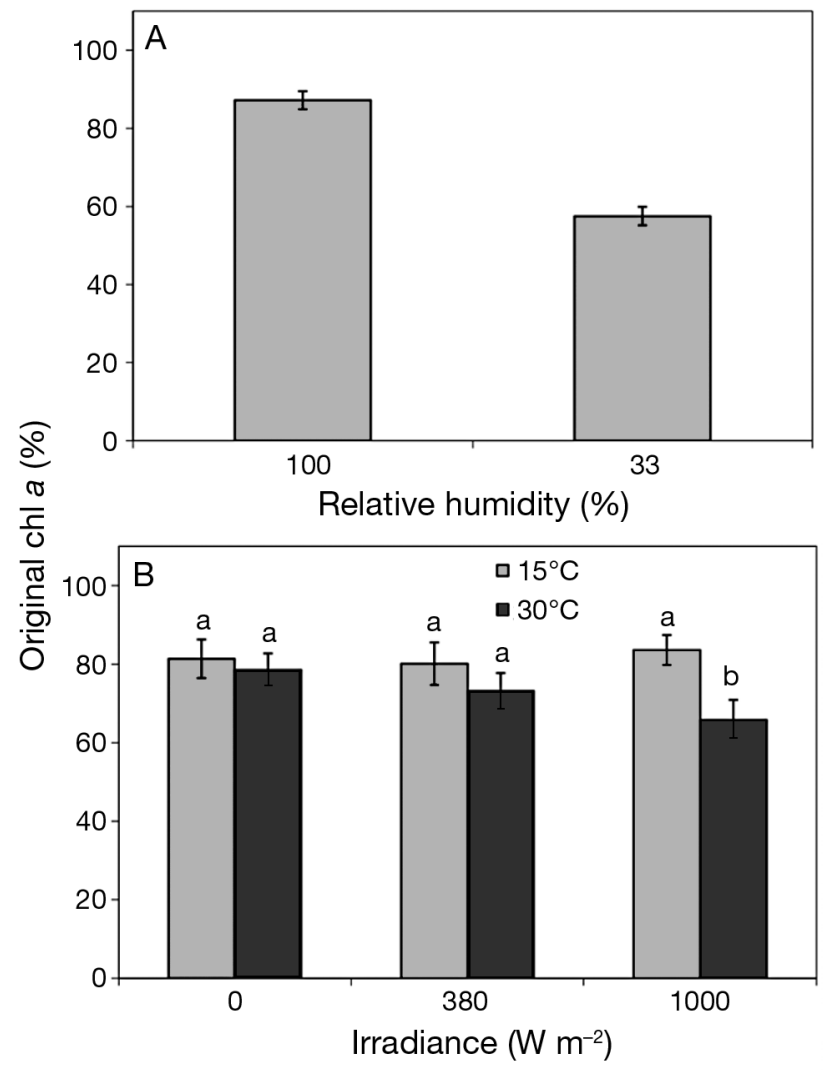

Fig. 3. Calliarthron tuberculosum. Pigment lost (mean \pm SE) after $30 \mathrm{~min}$ of emersion stress. (A) Effect of desiccation and (B) interactive effects of light and temperature. Different letters indicate significant differences (Tukey's HSD, $p<0.05$ )

\section{Bleaching of emersed fronds}

Emersed fronds were bleached in the laboratory under various combinations of temperature, light, and humidity. The individual and interactive effects of environmental stressors varied through time.

After $30 \mathrm{~min}$, there was a significant effect of humidity (Table 2). Fronds held at $100 \%$ RH retained $87.8 \pm$ $2.3 \%$ (mean \pm SEM) of their original pigment, while fronds held at $33 \% \mathrm{RH}$ lost significantly more pigment, retaining only $57.5 \pm 2.4 \%$ of their original pigment (Fig. 3A). In addition, there was a significant interaction between light and temperature (Table 2). The $30^{\circ} \mathrm{C}$ temperature treatment induced significantly more bleaching $(65.8 \pm 5.1 \%$ pigment remaining $)$, but only when combined with bright light (Fig. 3B; Tukey's HSD, $\mathrm{p}<0.05)$. Light did not significantly affect pigment loss when samples were tested at $15^{\circ} \mathrm{C}$.

After $60 \mathrm{~min}$, there were significant interactions between humidity and temperature and between humidity and light (Table 2). Humidity had a strong effect on pigment loss. Samples held at $100 \%$ RH lost significantly more pigment under bright lights than under dark or dim conditions (Fig. 4A; Tukey's HSD,

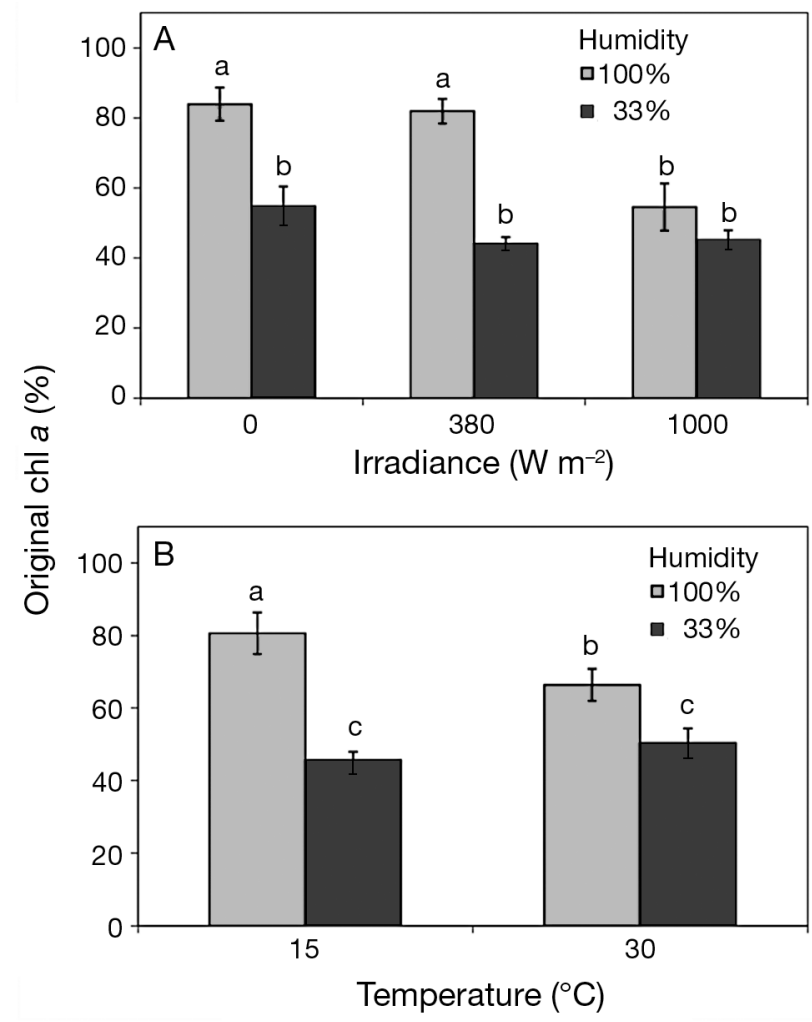

Fig. 4. Calliarthron tuberculosum. Pigment lost (mean \pm SE) after 60 min of emersion stress. (A) Interactive effects of desiccation and light, and (B) interactive effects of desiccation and temperature. Different letters indicate significant differences (Tukey's HSD, p < 0.05) 
Table 2. ANOVA results after 30,60, and 120 min of emersion stress. Bold indicates significant effect. Temp: temperature

\begin{tabular}{|c|c|c|c|c|c|}
\hline Duration & Effect & df & $S S$ & $F$ Ratio & $\mathrm{p}$ \\
\hline \multirow[t]{7}{*}{$30 \mathrm{~min}$} & Light & 2 & 0.06 & 1.05 & 0.36 \\
\hline & Temp & 1 & 0.17 & 6.41 & $<0.01$ \\
\hline & Humid & 1 & 2.23 & 84.64 & $<0.001$ \\
\hline & Light $\times$ Temp & 2 & 0.20 & 3.86 & $<0.05$ \\
\hline & Light $\times$ Humid & 2 & 0.02 & 0.29 & 0.75 \\
\hline & Temp $\times$ Humid & 1 & 0.02 & 0.64 & 0.43 \\
\hline & Light $\times$ Temp $\times$ Humid & 2 & 0.01 & 0.10 & 0.90 \\
\hline \multirow[t]{7}{*}{$60 \mathrm{~min}$} & Light & 2 & 0.48 & 10.59 & $<0.001$ \\
\hline & Temp & 1 & 0.06 & 2.46 & 0.12 \\
\hline & Humid & 1 & 1.19 & 52.43 & $<0.001$ \\
\hline & Light $\times$ Temp & 2 & 0.06 & 1.26 & 0.29 \\
\hline & Light $\times$ Humid & 2 & 0.27 & 5.94 & $<0.01$ \\
\hline & Temp $\times$ Humid & 1 & 0.19 & 8.56 & $<0.01$ \\
\hline & Light $\times$ Temp $\times$ Humid & 2 & 0.10 & 2.11 & 0.13 \\
\hline \multirow[t]{7}{*}{$120 \min$} & Light & 2 & 0.99 & 35.24 & $<0.001$ \\
\hline & Temp & 1 & 0.01 & 1.04 & 0.31 \\
\hline & Humid & 1 & 0.91 & 64.63 & $<0.001$ \\
\hline & Light $\times$ Temp & 2 & 0.07 & 2.63 & 0.08 \\
\hline & Light $\times$ Humid & 2 & 0.35 & 12.56 & $<0.001$ \\
\hline & Temp $\times$ Humid & 1 & 0.00 & 0.03 & 0.86 \\
\hline & Light $\times$ Temp $\times$ Humid & 2 & 0.13 & 4.75 & $<0.01$ \\
\hline
\end{tabular}

$\mathrm{p}<0.05)$. However, when humidity was reduced to $33 \% \mathrm{RH}$, the amount of pigment lost by fronds was not different across light levels (approx. 50\%; Fig. 4A). Samples held at $100 \% \mathrm{RH}$ lost significantly more pigment at $30^{\circ} \mathrm{C}$ than at $15^{\circ} \mathrm{C}$ (Fig. 4B). However, when humidity was reduced to $33 \% \mathrm{RH}$, pigmentation was significantly reduced compared to high humidity treatments and was not different among temperatures (Fig. 4B; Tukey's HSD, p < 0.05).

After $120 \mathrm{~min}$, there was a significant 3-way interaction among environmental stressors (Table 2). Tukey's HSD was unable to resolve significant differences among most treatments, so all comparisons were made to the least stressful cold-dark-humid treatment. Reducing humidity to $33 \% \mathrm{RH}$ induced significant bleaching (ca. 40 to $50 \%$ pigment remaining) across all temperature and light levels (Fig. 5; Tukey's HSD, p < 0.05). Regardless of humidity and temperature, bright light caused significant bleaching, and dim light caused significant bleaching only at $30^{\circ} \mathrm{C}$. Across all light and humidity treatments, elevated temperature did not significantly affect pigment loss (Fig. 5).

In sum, temperature, light, and desiccation stresses explained 60 to $70 \%$ of the variation in pigment loss over time (Fig. 6). After $30 \mathrm{~min}$, desiccation was the primary cause of bleaching, explaining $52.8 \%$ of the variation in pigmentation, while light and temperature had little effect $(0.1 \%$ and $3.4 \%$, respectively). The effect of desiccation remained significant but decreased slightly through time, explaining $33.8 \%$ of pigment loss after $60 \mathrm{~min}$ and $28.0 \%$ of pigment loss after $120 \mathrm{~min}$ (Fig. 6). Conversely, the effect of light increased over time, explaining $12.6 \%$ of pigment loss after $60 \mathrm{~min}$ and $30.2 \%$ of pigment loss after $120 \mathrm{~min}$. Temperature had a negligible effect on pigment loss over time, explaining just $1.0 \%$ of the variation after $60 \mathrm{~min}$ and $0.0 \%$ of the variation after $120 \mathrm{~min}$ (Fig. 6). Interactive effects among stressors increased over time, explaining $5.8 \%$ of pigment loss after $30 \mathrm{~min}$, $13.3 \%$ of pigment loss after $60 \mathrm{~min}$, and $15.4 \%$ of pigment loss after $120 \mathrm{~min}$.

\section{Time to $50 \%$ bleached}

Fronds monitored in the dark at $15^{\circ} \mathrm{C}$ and $100 \% \mathrm{RH}$ ('Null' treatment) did not significantly bleach over the course of the experiments, and were predicted to retain pigmentation for at least $5 \mathrm{~h}$, on average, and perhaps longer (Fig. 7). Individually, bright light and low humidity caused bleaching to significantly accelerate, causing fronds to bleach in $58.1 \pm 9.1 \mathrm{~min}$ (mean \pm SEM) and $42.0 \pm 4.9 \mathrm{~min}$, respectively. Increased temperature alone did not significantly affect bleaching rate (Fig. 7; Tukey's HSD, p < 0.05). Pairwise combinations of environmental stressors did not cause fronds to bleach significantly faster than bright light or low humidity alone. The most stressful treatment $\left(30^{\circ} \mathrm{C}\right.$, $1000 \mathrm{~W} \mathrm{~m} \mathrm{~m}^{-2}, 33 \% \mathrm{RH}$ ) caused fronds to bleach after $24.0 \pm 5.1 \mathrm{~min}$ (Fig. 7).

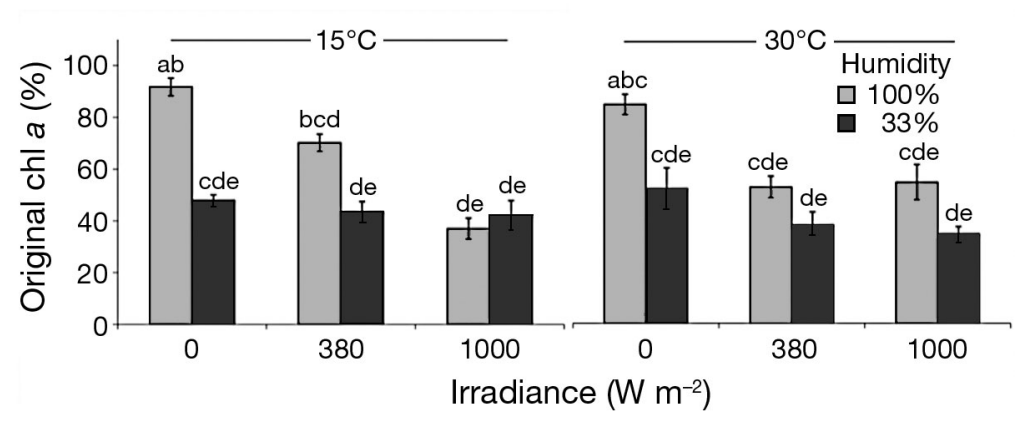

Fig. 5. Calliarthron tuberculosum. Pigment lost (mean \pm SE) after 120 min of emersion stress, illustrating the interactive effects of desiccation, light, and temperature. Different letters indicate significant differences (Tukey's HSD, $\mathrm{p}<0.05)$ 


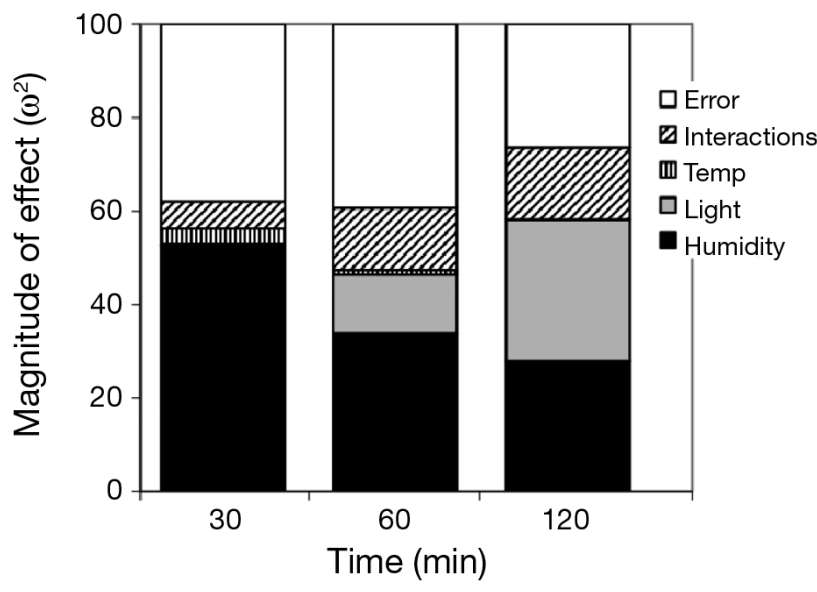

Fig. 6. Calliarthron tuberculosum. Relative contribution of environmental stressors to bleaching of emersed fronds over time

\section{DISCUSSION}

Intertidal seaweeds must cope with a suite of physiological stressors when low tides coincide with hot sunny weather (Davison \& Pearson 1996). Increased irradiance, temperature, and desiccation stresses may act independently or in combination to damage algal thalli and cause them to 'bleach' (e.g. Hodgson 1981, Kain \& Norton 1990, Scrosati \& DeWreede 1998, Hunt $\&$ Denny 2008). Some intertidal seaweeds, such as the coralline Calliarthron tuberculosum, are commonly relegated to tidepools, suggesting that one or more of these physiological stressors limits their emergence. In the present study, we carefully controlled environmental parameters in the laboratory to explore their indi-

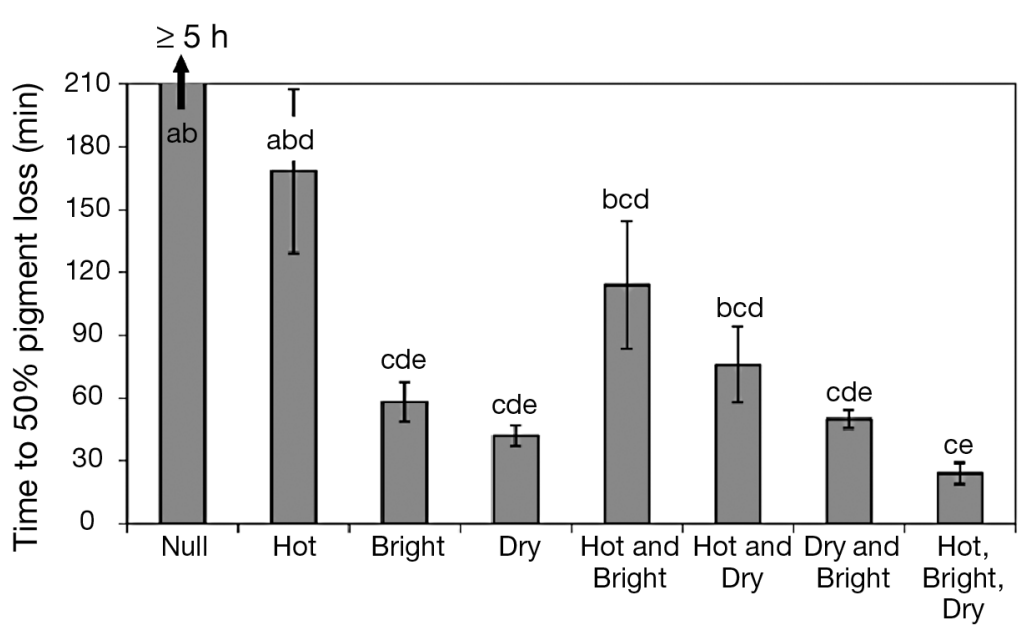

Fig. 7. Calliarthron tuberculosum. Time (mean \pm SE) to $50 \%$ pigment loss of emersed fronds under different stressor combinations. See 'Materials and methods' for details. Experimental fronds emersed in the 'Null' treatment $\left(15^{\circ} \mathrm{C}, 0 \mathrm{~W} \mathrm{~m}{ }^{-2}\right.$, and $\left.100 \% \mathrm{RH}\right)$ were predicted to retain pigmentation after $5 \mathrm{~h}$ of emersion. Different letters indicate significant differences (Tukey's HSD, $\mathrm{p}<0.05)$ vidual and combined effects on pigment degradation and, for the first time, describe the underlying cause of bleaching events in the field.

\section{Submerged intertidal fronds rarely bleach}

Although fronds of the coralline alga Calliarthron tuberculosum are often found bleached near the periphery of tidepools, data presented here suggest that significant bleaching does not occur when fronds of C. tuberculosum are submerged. Although experimental fronds started to bleach when submerged in $30^{\circ} \mathrm{C}$ seawater for $3 \mathrm{~h}$, it is unlikely that tidepools at HMS reach and sustain this high temperature for longer than $3 \mathrm{~h}$ to induce additional pigment loss. Nevertheless, Helmuth \& Hofmann (2001) recorded a maximum temperature of $29.8^{\circ} \mathrm{C}$ in a small tidepool at HMS, and we cannot rule out the possibility that slightly cooler temperatures sustained for a longer duration may also induce bleaching. Our data suggest that bleached fronds were more likely to have been physiologically stressed when emersed during previous low tides and then lost pigmentation over the course of re-immersion. Experimentally stressed fronds would often appear healthy for several hours after treatment, but would slowly lose pigmentation over several days when submerged in flowing seawater.

That submerged Calliarthron tuberculosum fronds do not bleach is in contrast to anecdotal accounts of subtidal C. tuberculosum fronds bleaching when kelp canopies are removed (M. Foster pers. comm.) and observations (P. T. Martone pers. obs.) of bleached C. tuberculosum growing deeply submerged (ca. $20 \mathrm{~cm}$ ) within tidepools along Vancouver Island, British Columbia, Canada. This suggests that fronds may exhibit local adaptation and differ in their susceptibility to environmental parameters, such as light. For example, intertidal fronds growing in central California, may be well-adapted to high light conditions and may be less susceptible to sudden increases in light exposure, possibly explaining why light did not have a strong effect on bleaching in experimental fronds. However, C. tuberculosum populations growing subtidally or intertidally under cloudy skies in coastal British Columbia are perhaps better adapted to low-light conditions and, therefore, more susceptible to bleaching when light suddenly increases. Future experiments could compare subtidal and intertidal populations or intertidal populations along a latitudinal 
gradient to resolve this putative effect of local adaptation and differential responses to environmental stress.

\section{Causes of bleaching in emersed corallines}

Although temperature and light stresses exacerbated the extent of bleaching through time, data presented here suggest that desiccation is the strongest driver of bleaching in intertidal Calliarthron tuberculosum fronds. The low humidity treatment was sufficient to induce bleaching in C. tuberculosum fronds regardless of light or temperature: desiccating fronds even bleached in complete darkness at $15^{\circ} \mathrm{C}$. This conclusion is supported by several other studies that also found desiccation to be the most harmful intertidal stress affecting seaweeds (Hodgson 1981, Smith \& Berry 1986, Matta \& Chapman 1995) and a significant driver of intertidal zonation patterns (e.g. Biebl 1952, Johnson et al. 1974). Susceptibility of C. tuberculosum to desiccation stress during low tides may be linked to its sparsely branched morphology and low water content (28.3\% wet mass) (Padilla 1984, Bell 1995) and may explain why mid-intertidal $C$. tuberculosum are rarely found growing out of tidepools, even in shaded habitats or cooler climates, such as the Pacific coast of Vancouver Island.

The extent of bleaching due to desiccation was undoubtedly linked, at least in part, to the extremely low humidity (33\% RH) selected for the experiments. Although extreme, this $\mathrm{RH}$ value is not unrealistic. The average RH recorded at HMS every 10 min from $1 \mathrm{Au}-$ gust 2006 to 5 May 2009 was $80.6 \pm 11.6 \%$ (mean \pm SD) (M. W. Denny pers. comm.). However, warm sunny weather often led to a significant reduction in relative humidity. From 2006 to 2009, when air temperature exceeded $20^{\circ} \mathrm{C}$ the average $\mathrm{RH}$ was $50.2 \pm 15.5 \%$, and when air temperature exceeded $25^{\circ} \mathrm{C}$ the average $\mathrm{RH}$ was $31.8 \pm 9.8 \%$. At 50 and $80 \% \mathrm{RH}$, desiccation would likely occur more slowly, perhaps reducing the rate or extent of bleaching and, concomitantly, the statistical significance of this experimental factor. This uncertainty and inability to predict responses to alternative untested treatments is one major limitation of the factorial experimental design used here. Nevertheless, because coralline algae predominantly bleach during warm sunny weather, desiccation stress is expected to be highly significant.

Desiccation increases the production of reactive oxygen species (ROS), which are known to cause significant intercellular damage (Vicré et al. 2004, Kranner \& Birtic 2005). In particular, ROS have been directly linked to pigment degradation in coralline algae; bleaching in the coralline Corallina officinalis was sig- nificantly reduced by the addition of antioxidants (Latham 2008). Desiccation also adversely affects cellular membranes (e.g. Dhindsa \& Bewley 1977, Hurd \& Dring 1991) and may be especially damaging to the plasmalemma of coralline algal cells, which are encased within rigidly calcified cell walls that do not shrink with water loss. As coralline cells dehydrate, contract, and recede from surrounding calcified walls, plasma membranes may tear. Such plasmolysis has not been reported in desiccating corallines, but it has been documented in desiccating plants (Vicré et al. 2004) and osmotically stressed algae (Biebl 1962, Lobban \& Harrison 1997), and is often, but not always, irreparable (see Pollock \& Pickett-Heaps 2005). It is interesting to note that the closely-related articulated coralline Corallina vancouveriensis is able to survive out of tidepools and live much higher on the shore because its finely branched morphology traps water and thereby delays desiccation during low tides (Padilla 1984).

Although desiccation had the strongest effect on pigment degradation, light played an increasingly important role through time (Fig. 6). For example, after 30 min of emersion, bright light only induced bleaching when combined with high temperature (Fig. 3A). However, after $1 \mathrm{~h}$ of emergence, the amount of bleaching induced by the bright light and low humidity treatments was not significantly different (Fig. 4A), and after $2 \mathrm{~h}$ of emergence, variance in light and humidity explained a similar amount of the overall variation in frond pigmentation (Fig. 6). Although light quantity and quality have been shown to affect pigmentation in marine macroalgae (e.g. Beach \& Smith 1996, Häder \& Figueroa 1997, Clark et al. 2004) including corallines (e.g. Algarra et al. 1991, Irving et al. 2004), light stress may have less of an effect on photosynthetic performance than desiccation (Hodgson 1981, Matta \& Chapman 1995). Results presented here support these conclusions.

Temperature had little effect on bleaching in Calliarthron tuberculosum compared to light and desiccation. Although high temperatures have been previously shown to induce bleaching in submerged coralline algae, fronds had to be heated for several days to cause significant pigment loss (Latham 2008), a result that has little relevance for tidepools along temperate rocky shores. Past studies have also reported only a marginal effect of high temperature stress on the photosynthetic performance of emersed intertidal macroalgae (Hodgson 1981, Smith \& Berry 1986, Matta \& Chapman 1995). For example, Smith \& Berry (1986) noted that temperature tolerance was not a good predictor of intertidal zonation patterns and suggested that other physiological indicators, e.g. desiccation resistance, might be more useful in predicting vertical distributions. Surprisingly, although not statistically significant, data suggest 
that elevated temperatures may slow bleaching rates when combined with light or desiccation stresses (Fig. 7). This result is intriguing and merits further study. One hypothesis would be that an up-regulated heat shock response delays damage incurred by light and desiccation stress. HSPs are known to protect organisms from a variety of abiotic stressors (Feder \& Hofmann 1999, Sorensen et al. 2010) and, specifically, recent studies have commented on the beneficial effects of HSP up-regulation in resisting desiccation stress (Pearson et al. 2009, Mizrahi et al. 2010).

\section{Coralline bleaching vs. coral bleaching}

Bleaching in coralline algae is not to be confused with bleaching observed in tropical coral reefs. Unlike bleaching in coralline algae, bleaching in corals generally results from the dissociation of symbiotic unicellular algae from animal host tissue, although in some cases, the photosynthetic pigments of the algal symbionts are also affected (reviewed in Brown 1997). Past research has clearly demonstrated that temperature and light stresses both induce bleaching in corals (e.g. Hoegh-Guldberg \& Smith 1989, Lesser et al. 1990, Brown et al. 1994, Fitt \& Warner 1995, Lesser \& Farrell 2004), and recently Anthony \& Kerswell (2007) demonstrated that, like many intertidal corallines, intertidal corals are also susceptible to desiccation stress. During an extreme low tide, wave-exposed corals that were wetted by incoming waves maintained their coloration whereas wave-protected corals dried out and bleached (Anthony \& Kerswell 2007). Bleaching in corals is often caused by oxidative stress imposed by ROS generated by climatic stressors (Lesser et al. 1990, Lesser 1996, Lesser \& Farrell 2004), as demonstrated for the coralline Corallina (Latham 2008) and argued here for the coralline Calliarthron tuberculosum. Thus, although mechanistically distinct, bleaching in corals and coralline algae may be physiologically comparable.

\section{Bleaching predictions}

Physiological data, such as those presented here, are needed to generate mechanistic models of ecological responses to environmental perturbations, including future climate scenarios (Denny \& Helmuth 2009, Denny et al. 2009). For example, data on the individual and interactive effects of environmental stressors on Calliarthron tuberculosum pigmentation could be used in conjunction with tide and weather data to predict the frequency of bleaching events along the shore. Such 'ecomechanical' models would lend quantitative insight into the observed distribution of C. tuberculo- sum along the shore and would allow various 'what-if' climate scenarios to be explored using newly emerging statistical methods (Denny et al. 2009). For example, if thallus desiccation is the primary cause of bleaching and desiccation is affected by wind speed, air temperature, and irradiance (Bell 1995), future studies could predict the likelihood that intertidal fronds might bleach when exposed by low tides on windy, bright, sunny days. Further, they could explore potential increases in bleaching frequency if air temperatures were $2^{\circ} \mathrm{C}$ warmer or if desiccating winds blew $10 \mathrm{mph}$ $\left(16 \mathrm{~km} \mathrm{~h}^{-1}\right.$ ) faster (see Denny et al. 2009). On the other hand, if submerged fronds are buffered from the effects of increased temperature and light, then fronds growing deep within tidepools might be impervious to the anticipated climatic effects of global warming. Given the likely impact of coralline bleaching on the structure of intertidal communities, such ecomechanical predictions could contribute directly to larger-scale ecological predictions.

Acknowledgements. This manuscript benefitted from comments made by P. Gabrielson, J. Jorve, K. Demes, R. Guenther, M. Denny, and 2 anonymous reviewers. Special thanks to $\mathrm{M}$. Denny for insightful conversations about intertidal stress and experimental design and to J. Watanabe and C. Harley for statistical advice. Thanks to the Somero Laboratory at Hopkins Marine Station for assisting with spectrophotometric measurements. L. Miller provided data on relative humidity in the field and ideas for controlling humidity in the lab. Funding was generously provided by the National Science Foundation (IOS-0641068) to M. Denny and the Natural Sciences and Engineering Research Council of Canada (356403-09) to P.T.M. This is contribution number 375 from PISCO, the Partnership for Interdisciplinary Studies of Coastal Oceans, funded primarily by the Gordon and Betty Moore Foundation and the David and Lucile Packard Foundation.

\section{LITERATURE CITED}

Akioka H, Baba M, Masaki T, Johansen HW (1999) Rocky shore turfs dominated by Corallina (Corallinales, Rhodophyta) in Northern Japan. Phycological Res 47:199-206

Algarra P, de la Viña G, Niell J (1991) Effects of light quality and irradiance level interactions on short-term pigment response of the red alga Corallina elongata. Mar Ecol Prog Ser 74:27-32

Anthony KRN, Kerswell AP (2007) Coral mortality following extreme low tides and high solar radiation. Mar Biol 151: 1623-1631

Beach KS, Smith CM (1996) Ecophysiology of tropical rhodophytes. I. Microscale acclimation in pigmentation. J Phycol 32:701-710

Bell EC (1993) Photosynthetic response to temperature and desiccation of the intertidal alga Mastocarpus papillatus. Mar Biol 117:337-346

> Bell EC (1995) Environmental and morphological influences on thallus temperature and desiccation of the intertidal alga Mastocarpus papillatus Kutzing. J Exp Mar Biol Ecol 191:29-55 
Biebl R (1952) Ecological and non-environmental constitutional resistance of the protoplasm of marine algae. J Mar Biol Assoc UK 31:307-315

Biebl R (1962) Seaweeds. In: Lewin RA (ed) Physiology and biochemistry of the Algae. Academic Press, New York, NY, p 799-815

> Brown BE (1997) Coral bleaching: causes and consequences. Coral Reefs 16:S129-S138

Brown BE, Dunne RP, Scoffin TP, Le Tissier MDA (1994) Solar damage in intertidal corals. Mar Ecol Prog Ser 105: $219-230$

> Clark RP, Edwards MS, Foster MS (2004) Effects of shade from multiple kelp canopies on an understory algal assemblage. Mar Ecol Prog Ser 267:107-119

> Davison IR, Pearson GA (1996) Stress tolerance in intertidal seaweeds. J Phycol 32:197-211

Denny M, Helmuth B (2009) Confronting the physiological bottleneck: a challenge from ecomechanics. Integr Comp Biol 49:197-201

> Denny M, Hunt LJH, Miller LP, Harley CDG (2009) On the prediction of extreme ecological events. Ecol Monogr 79: 397-421

> Dhindsa RS, Bewley JD (1977) Water stress and protein synthesis. V. Protein synthesis, protein stability, and membrane permeability in a drought-sensitive and a drought-tolerant moss. Plant Physiol 59:295-300

Dommasnes A (1968) Variations in the meiofauna of Corallina officinalis L. with wave exposure. Sarsia 34:117-124

> Feder ME, Hofmann GE (1999) Heat-shock proteins, molecular chaperones, and the stress response: evolutionary and ecological physiology. Annu Rev Physiol 61:243-282

Figueiredo MAdO, Kain JM, Norton TA (2000) Responses of crustose corallines to epiphyte and canopy cover. J Phycol 36:17-24

Fitt WK, Warner ME (1995) Bleaching patterns of four species of Caribbean reef corals. Biol Bull 189:298-307

> Fork DC, Bose S, Herbert SK (1986) Radiationless transitions as a protective mechanism against photoinhibition in higher plants and a red alga. Photosynth Res 10:327-333

Graham MH, Edwards MS (2001) Statistical significance versus fit: estimating the importance of individual factors in ecological analysis of variance. Oikos 93:505-513

Häder DP, Figueroa FL (1997) Photoecophysiology of marine algae. Photochem Photobiol 66:1-14

> Harley CDG, Paine RT (2009) Contingencies and compounded rare perturbations dictate sudden distributional shifts during periods of gradual climate change. Proc Natl Acad Sci USA 106:11172-11176

Hay ME (1981) The functional morphology of turf-forming seaweeds: persistence in stressful marine habitats. Ecology 62:739-750

Helmuth BST, Hofmann GE (2001) Microhabitats, thermal heterogeneity, and patterns of physiological stress in the rocky intertidal zone. Biol Bull 201:374-384

> Henkel SK, Hofmann GE (2008) Differing patterns of hsp70 gene expression in invasive and native kelp species: evidence for acclimation-induced variation. J Appl Phycol 20:915-924

Hodgson LM (1981) Photosynthesis of the red alga Gastroclonium coulteri (Rhodophyta) in response to changes in temperature, light intensity, and desiccation. J Phycol 17: 37-42

Hoegh-Guldberg O, Smith GJ (1989) The effect of sudden changes in temperature, light and salinity on the population density and export of zooxanthellae from the reef corals Stylophora pistillata Esper and Seriatopora hystrix Dana. J Exp Mar Biol Ecol 129:279-304
Hunt LJH, Denny MW (2008) Desiccation protection and disruption: a trade-off for an intertidal marine alga. J Phycol 44:1164-1170

Hurd C, Dring MJ (1991) Desiccation and phosphate uptake by intertidal fucoid algae in relation to zonation. Br Phycol J 26:327-333

> Irving AD, Connell SD, Elsdon TS (2004) Effects of kelp canopies on bleaching and photosynthetic activity of encrusting coralline algae. J Exp Mar Biol Ecol 310:1-12

Jeffrey SW, Humphrey GF (1975) New spectrophotometric equations for determining chlorophylls $a, b, c_{1}$, and $c_{2}$ in higher plants, algae and natural phytoplankton. Biochem Physiol Pflanz 167:191-194

> Johnson WS, Gigon A, Gulmon SL, Mooney HA (1974) Comparative photosynthetic capacities of intertidal algae under exposed and submerged conditions. Ecology 55:450-453

Kain JM, Norton TA (1990) Marine ecology. In: Cole KM, Sheath RG (eds) Biology of the red algae. Cambridge University Press, New York, NY, p 377-422

- Kelaher BP (2002) Influence of physical characteristics of coralline turf on associated macrofaunal assemblages. Mar Ecol Prog Ser 232:141-148

Kranner I, Birtic S (2005) A modulating role for antioxidants in desiccation tolerance. Integr Comp Biol 45:734-740

- Latham H (2008) Temperature stress-induced bleaching of the coralline alga Corallina officinalis: a role for the enzyme bromoperoxidase. Bioscience Horizons 1:104-113

Lesser MP (1996) Exposure of symbiotic dinoflagellates to elevated temperatures and ultraviolet radiation causes oxidative stress and photosynthesis. Limnol Oceanogr 41: 271-283

> Lesser MP, Farrell JH (2004) Exposure to solar radiation increases damage to both host tissues and algal symbionts of corals during thermal stress. Coral Reefs 23:367-377

Lesser MP, Stochaj WR, Tapley DW, Shick JM (1990) Bleaching in coral reef anthozoans: effects of irradiance, ultraviolet radiation, and temperature on the activities of protective enzymes against active oxygen. Coral Reefs 8: 225-232

> Li R, Brawley SH (2004) Improved survival under heat stress in intertidal embryos (Fucus spp.) simultaneously exposed to hypersalinity and the effect of parental thermal history. Mar Biol 144:205-213

Lipkin Y, Beer S, Eshel A (1993) The ability of Porphyra linearis (Rhodophyta) to tolerate prolonged periods of desiccation. Bot Mar 36:517-523

Lobban CS, Harrison PJ (1997) Seaweed ecology and physiology. Cambridge University Press, Cambridge

Mathieson AC, Burns RL (1971) Ecological studies of economic red algae. I. Photosynthsis and respiration of Chondrus crispus Stackhouse and Gigartina stellata (Stackhouse) Batters. J Exp Mar Biol Ecol 7:197-206

Matta JL, Chapman DJ (1995) Effects of light, temperature and desiccation on the net emersed productivity of the intertidal macroalga Colpomenia peregrina Sauv. (Hamel). J Exp Mar Biol Ecol 189:13-27

Mizrahi T, Heller J, Goldenberg S, Arad Z (2010) Heat shock proteins and resistance to desiccation in congeneric land snails. Cell Stress Chaperones 15:351-363

Mykles DL, Ghalambor CK, Stillman JH, Tomanek L (2010) Grand challenges in comparative physiology: integration across disciplines and across levels of biological organization. Integr Comp Biol 50:6-16

> Oates BR (1985) Photosynthesis and amelioration of desiccation in the intertidal saccate alga Colpomenia peregrina. Mar Biol 89:109-119

Padilla DK (1984) The importance of form: differences in com- 
petitive ability, resistance to consumers and environmental stress in an assemblage of coralline algae. J Exp Mar Biol Ecol 79:105-127

Paine RT (1984) Ecological determinism in the competition for space. Ecology 65:1339-1348

Pearson GA, Hoarau G, Lago-Leston A, Coyer JA and others (2009) An expressed sequence tag analysis of the intertidal brown seaweeds Fucus serratus (L.) and F. vesiculosus (L.) (Heterokontophyta, Phaeophyceae) in response to abiotic stressors. Mar Biotechnol 12:195-213

Pollock FM, Pickett-Heaps D (2005) Spatial determinants in morphogenesis: recovery from plasmolysis in the diatom Ditylum. Cell Motil Cytoskeleton 60:71-82

Portner HO (2010) Oxygen- and capacity-limitation of thermal tolerance: a matrix for integrating climate-related stressor effects in marine ecosystems. J Exp Biol 213: 881-893

Rumrill S, Cameron R (1983) Effects of gamma-aminobutryic acid on the settlement of larvae of the black chiton Katharina tunicata. Mar Biol 72:243-247

Scrosati R, DeWreede RE (1998) The impact of frond crowding on frond bleaching in the clonal intertidal alga Mazzaella cornucopiae (Rhodophyta, Gigartinaceae) from British Columbia, Canada. J Phycol 34:228-232

Smith CM, Berry JA (1986) Recovery of photosynthesis after

Editorial responsibility: Brian Helmuth,

Columbia, South Carolina, USA exposure of intertidal algae to osmotic and temperature stresses: comparative studies of species with differing distributional limits. Oecologia 70:6-12

Somero GN (2010) The physiology of climate change: how potentials for acclimatization and genetic adaptation will determine 'winners' and 'losers'. J Exp Biol 213:912-920

Sorensen JG, Heckmann LH, Holmstrup M (2010) Temporal gene expression profiles in a palaearctic springtail as induced by desiccation, cold exposure and during recovery. Funct Ecol 24:838-846

Steneck RS (1986) The ecology of coralline algal crusts: convergent patterns and adaptive strategies. Annu Rev Ecol Syst 17:273-303

Taylor PR, Hay ME (1984) Functional morphology of intertidal seaweeds: adaptive significance of aggregate vs. solitary forms. Mar Ecol Prog Ser 18:295-302

Vicré M, Farrant JM, Driouich A (2004) Insights into the cellular mechanisms of desiccation tolerance among angiosperm resurrection plant species. Plant Cell Environ 27: 1329-1340

Williams EA, Craigie A, Yeates A, Degnan SM (2008) Articulated coralline algae of the genus Amphiroa are highly effective natural inducers of settlement in the tropical abalone Haliotis asinina. Biol Bull 215:98-107

Submitted: March 3, 2010; Accepted: August 23, 2010 Proofs received from author(s): September 24, 2010 